\title{
A study of the Convection Heat Transfer Coefficients of Grinding Fluids
}

\author{
T. Jin, D. J. Stephenson (1) \\ Cranfield University, Cranfield, UK
}

\begin{abstract}
By using hydrodynamic and thermal modelling, the variation of the convection heat transfer coefficient (CHTC) of the process fluids within the grinding zone has been investigated. Experimental measurements of $\mathrm{CHTC}$ for different grinding fluids have been undertaken and show that the CHTC depends on the grinding wheel speed and the fluid film thickness within the contact zone. The film thickness is determined by grinding wheel speed, porosity, grain size, fluid type, flow rate and nozzle size. The CHTC values are compared for a wide range of grinding regimes, including HEDG, creep feed and finish grinding.
\end{abstract}

Keywords: Modelling, Grinding, Fluid

\section{INTRODUCTION}

Cooling by the process fluids plays a crucial role in grinding to avoid thermal damage to the workpiece surface. This is especially important for deep grinding, such as creep feed grinding and high efficiency deep grinding (HEDG) where high thermal energy is produced due to the high material removal rates used. The cooling efficiency can be quantified by the convection heat transfer coefficient ( $\mathrm{CHTC}$ ) of the fluid, which is an important variable determining the amount and ratio of the heat convected away and hence the subsequent workpiece surface temperature. To predict the grinding temperatures, it is preferable that an accurate value of $\mathrm{CHTC}$ of the fluid is known. Unfortunately it is not easy to measure or calculate this value and even order of magnitude estimation is considered to be difficult. Therefore most previous research has concentrated on the energy partition of the total grinding heat in order to estimate the temperatures, whilst the energy partition coefficient is usually obtained by matching the theoretical and measured temperatures within the grinding zone [1-3].

In this paper, the CHTCs of fluids under different grinding conditions have been predicted by coupled fluid dynamic and thermal modelling. A special test rig, with thermocouples embedded at different distances to the grinding surface, has been used to measure the heat flux to the workpiece, which is used to calculate the CHTCs of grinding fluids. The theoretical predictions show good agreement with the experimental results. It has been found that, the CHTCs under forced convection conditions due to the high grinding wheel speeds are much higher than the values previously reported.

\section{COUPLED HYDROTHERMAL MODELING TO PREDICT THE CHTC OF GRINDING FLUIDS}

Figure 1 shows the temperature profile of the grinding fluid in the thermal boundary layer between the wheel and workpiece surface. The workpiece surface temperature, $T_{w}$, is simplified as being uniformly distributed, while the bulk temperature of grinding fluid outside the boundary layer is $T_{\infty} . . \quad \delta_{t}$ is the thickness of the thermal boundary layer at location $x$. The bulk velocity of grinding fluid is assumed equal to the grinding wheel peripheral speed $v_{s}$, and this has been validated in the hydrodynamic analysis for the grinding fluid flow. At the workpiece surface, the local heat flux $q_{f}$ to the fluid can be expressed as

$$
\left.q_{f}=-k \frac{\partial T}{\partial y}\right]_{w}=h_{f}\left(T_{w}-T_{\infty}\right)
$$

where $k$ is the thermal conductivity of coolant and $h_{f}$ is the convection heat transfer coefficient.
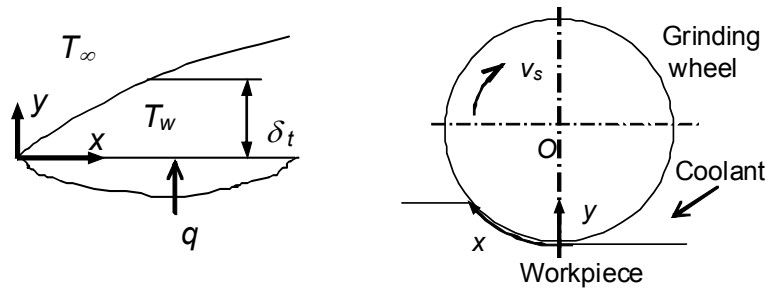

Figure 1: Thermal boundary layer of grinding fluid on the workpiece surface.

To obtain the value of $h_{f}$, the fluid temperature gradient at the workpiece surface is needed. The conditions that the temperature distribution within the fluid must satisfy are as follows:

$$
\begin{aligned}
& T=T_{w}, \quad \text { at } y=0 \\
& \frac{\partial T}{\partial y}=0, \quad T=T \infty, \quad \text { at } \quad y=\delta_{t}
\end{aligned}
$$

The simplified energy equation for incompressible flow neglecting the viscous dissipation is:

$$
u \frac{\partial T}{\partial x}+v \frac{\partial T}{\partial y}=\alpha \frac{\partial^{2} T}{\partial y^{2}}
$$

At $y=0$ with no viscous heating 


$$
\frac{\partial^{2} T}{\partial \mathrm{y}^{2}}=0
$$

The equations 2 and 4 can be fitted to a cubic polynomial:

$$
\frac{T-T_{w}}{T_{\infty}-T_{w}}=\frac{3}{2} \frac{y}{\delta_{t}}-\frac{1}{2}\left(\frac{y}{\delta_{t}}\right)^{3}
$$

The grinding width of the wheel is generally much larger than the interconnected porosity spacing in the wheel and fluid penetration depth, so the fluid flow is taken as two dimensional, i.e., no side flow in the axial direction of the wheel. According to the Navier-Stokes equation for steady state motion in the infinitely wide grinding gap

$$
\frac{\partial^{2} u}{\partial \mathrm{y}^{2}}=\frac{1}{\mu} \frac{\partial p}{\partial x}
$$

where $u$ is fluid flow velocity in $x$ direction and $\mu$ is dynamic viscosity of the grinding fluid. The boundary conditions are

$$
\begin{array}{lll}
u=0 & , \text { at } & y=0 \\
u=v_{s} & , \text { at } & y=\delta
\end{array}
$$

where $\delta$ is the coolant film thickness within the grinding zone, $v_{s}$ is grinding wheel speed, $p$ is the coolant pressure. By solving equation (6) with the boundary condition, the flow velocity can be expressed as

$$
u=\frac{1}{\mu} \frac{\partial p}{\partial x} \frac{y^{2}}{2}+\left(\frac{v_{\mathrm{s}}}{\delta}-\frac{1}{2 \mu} \frac{\partial p}{\partial x} \delta\right) y
$$

The fluid mass flowing between wheel and workpiece can be calculated as

$$
m=b \rho \int_{0}^{\delta} u d y
$$

where $b$ is the grinding width, $\rho$ is the fluid density. By combining equations (7) and (8) the following expression for the pressure gradient can be derived:

$$
\frac{\partial p}{\partial x}=-\frac{12 \mu\left(m-v_{s} b \rho \delta / 2\right)}{b \rho \delta^{3}}=k_{1}
$$

For the parabolic distribution of $u$ along $y$ direction, the mass flow can be approximated as

$$
m=\frac{2}{3} v_{s} b \rho \delta
$$

So equation (9) can be simplified as

$$
\frac{\partial p}{\partial x}=-\frac{2 \mu v_{s}}{\delta^{2}}=k_{1}
$$

By considering the energy balance in a control volume within the grinding zone on the workpiece surface, Figure 2, the following equation can be obtained and used to derive the thermal boundary thickness $\delta_{t}[3]$ :

$$
\frac{d}{d x}\left[\int_{0}^{\delta_{t}}\left(T_{\infty}-T\right) u d y\right]+\frac{\mu}{\rho c}\left[\int_{0}^{\delta_{t}}\left(\frac{d u}{d y}\right)^{2} d y\right]=\left.\alpha \frac{\partial T}{\partial \mathrm{y}}\right|_{w}
$$

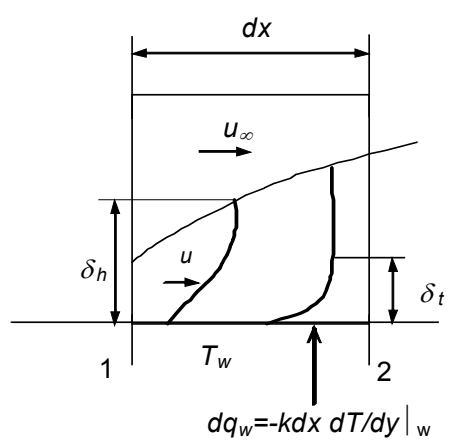

Figure 2: Control volume within the grinding zone for energy balance.

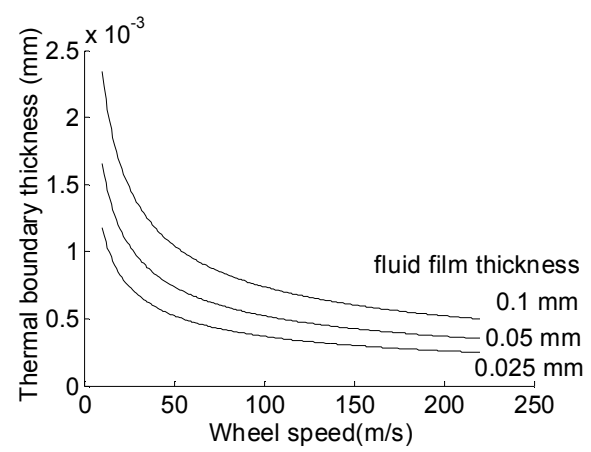

Figure 3: Thickness of thermal boundary within the grinding zone (water at room temperature).

Figure 3 shows that the thermal boundary layer thickness decreases when increasing the wheel speed and it is also affected by the overall fluid film thickness. The fluid film thickness is affected by the process conditions. Previous research shows that the film thickness at the grinding zone can be estimated through experimental measurements or theoretical analysis [5-8].

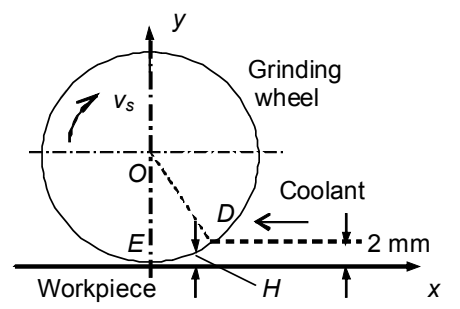

Figure 4: Schematic diagram of grinding with coolant supply.

According to Guo and Malkin [4], the following differential equations describing the tangential velocity of grinding fluid $u_{\theta}$ and depth of fluid penetration $h$ have been derived:

$$
u_{\theta} \frac{d u_{\theta}}{d \theta}-\frac{\mu R}{K_{p} \rho}\left(v_{s}-u_{\theta}\right)=0
$$

$\frac{u_{\theta}{ }^{2} h}{R} \frac{d^{2} h}{d \theta^{2}}-\frac{h^{2}}{R}\left(\frac{d u_{\theta}}{d \theta}\right)^{2}+\frac{2 u_{\theta} h}{R} \frac{d h}{d \theta} \frac{d u_{\theta}}{d \theta}$

$$
+\frac{\mu h u_{\theta}}{K_{p} \rho} \frac{d h}{d \theta}+u_{\theta}{ }^{2} h-\frac{p R}{\phi \rho}=0
$$

where $\theta$ is the angular position on the wheel surface covering angle $D O E$ starting from $O D, R$ is the wheel radius, $p$ is fluid pressure. The wheel surface is considered 
to have an effective porosity $\varphi$ for the fluid flow, it may vary from about 0.4 for conventional wheels to 0.9 for creep feed wheels. Only the ram pressure of the jet issuing out of the nozzle was considered by Guo and Malkin, which is appropriate when using low wheel speeds and relatively porous wheels. However, in deep grinding, high nozzle pressure and high wheel speed significantly increases the effects of the hydrodynamic pressure, which can not be ignored. In this paper the hydrodynamic pressure developed in the thin film between the wheel and workpiece has been taken into account.

The Reynolds equation governing the hydrodynamic pressure developed between the wheel and workpiece, covering the angular range of $D O E$ in Figure 4, can be written as [9 and10]

$$
\begin{aligned}
& \frac{\partial}{\partial x}\left(\frac{H^{3}}{\mu} \frac{\partial p}{\partial x}\right)=-6\left(v_{s} \cos (x / R)-v_{w}\right) \frac{\partial H}{\partial x} \\
& +H \frac{\partial\left(v_{s} \cos (x / R)+v_{w}\right)}{\partial x}-12 v_{s} \sin \left(\frac{x}{R}\right)
\end{aligned}
$$

where $H$ is the variable fluid film thickness at the entrance wedge, $v_{w}$ is the worktable speed. The range of $D O E$ is determined by wheel radius and fluid film thickness $t$ when the grinding coolant is modelled as a layer of fluid flowing on the workpiece surface toward the wedge. The value $t$ has been measured and found to range from 1 to $3 \mathrm{~mm}$ [4]. Within this range, the magnitude of $t$ has little effect on the depth of fluid penetration into the wheel. $t=2 \mathrm{~mm}$ was used in the following analysis, see Figure 4.

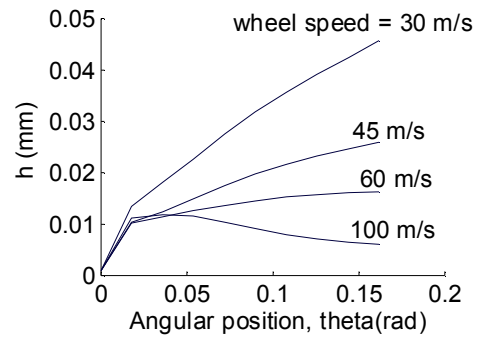

(a) without effect of hydrodynamic pressure.

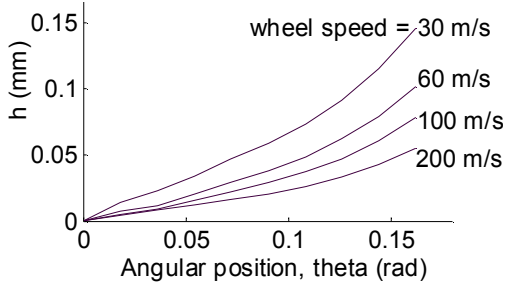

(b) with effect of hydrodynamic pressure.

Figure 5: Depth of coolant penetration on the wheel surface (water based fluid, $v_{0}=0.6 \mathrm{~m} / \mathrm{s}, d=0.2 \mathrm{~mm}, H_{0}=0.1 \mathrm{~mm}$ ).

Wheel:

electroplated CBN, B252, 200mm diameter

Wheel speed:

$50,146 \mathrm{~m} / \mathrm{s}$

Worktable speed $\quad 1 \mathrm{~mm} / \mathrm{s}$

Depth of cut: $\quad 0.4 \mathrm{~mm}$

Workpiece:

$51 \mathrm{CrV} 4$ steel

Table 1: Test conditions.
By solving equations (13), (14) and (15), the fluid flow through the grinding zone can be calculated. Figure 5(a) shows that the depth of fluid penetration at the junction point $E$ (Figure 3), which determines the fluid film thickness within the grinding zone, depends on the grinding wheel speed $(0.015 \sim 0.05 \mathrm{~mm}$ for wheel speed $60 \sim 30 \mathrm{~m} / \mathrm{s})$. Due to the influence of hydrodynamic pressure the depth of fluid penetration is predicted to be much higher in Figures 5(b). The upper bound value for the depth of fluid penetration is the grinding gap $H_{0}$ between wheel and work surface (Figure 4), which includes the effect of wheel porosity. For an average grain diameter $d=0.252 \mathrm{~mm}$, the minimum $H_{0} \approx$ $d / 2 \approx 0.13 \mathrm{~mm}$ for a non-porous wheel, although this could be a much larger value for porous wheels.

\section{EXPERIMENTAL MEASUREMENTS OF THE CHTC OF GRINDING FLUIDS}

A special test rig, with three $\mathrm{K}$ type thermocouples $(10 \mu \mathrm{m}$ thick) embedded beneath the sample surface, has been used to measure the heat flux to the workpiece (Figure 6). The rig is inclined at a $12^{\circ}$ angle, so that the temperatures at different depths from the ground surface can be measured.

The temperature readings from the three thermocouples were used to obtain the heat flux entering the workpiece surface, $q_{w}$ :

$$
\left.q_{w}=-k_{w} \frac{\partial T}{\partial y}\right]_{\mathcal{W}}=-k_{w} \frac{\Delta T}{\Delta y}
$$

where $k_{w}$ is the thermal conductivity of the workpiece material. The $\mathrm{CHTC}, h_{f}$, can then be obtained by using the following expression.

$$
q_{f}=q_{t}-q_{w}-q_{s}-q_{c h}=h_{f} \cdot\left(T_{w}-T_{\infty}\right)
$$

The total heat flux, $q_{t}$, was calculated from the specific grinding energy, SGE, based on the spindle power monitored and the grinding parameters [10]. The heat flux to the abrasives, $q_{s}$, was calculated by the Hahn model [11], and heat flux to grinding chips, $q_{c h}$, was estimated by assuming a constant chip temperature of $1000^{\circ} \mathrm{C}$. Tests were carried out under creep-feed grinding mode, see Table 1 , to avoid fluid burn-out and achieve low temperatures. Previous experimental study and detailed energy partitioning analysis shows that over $80-90 \%$ of the grinding energy can be taken away by the grinding fluids in creepfeed grinding $[12,13]$, the amount of heat taken away by the grinding chips and abrasive wheel takes no more than $5-6 \%$ of the total heat flux and thus has no major effect on the overall accuracy of the CHTCs calculated.

Three types of waterbased fluid and a mineral oil have been tested. Table 2 lists the average values of the SGE and CHTCs from the tests. The fluid film thickness is estimated to be around $0.13-0.15 \mathrm{~mm}$. Thermal properties of water and mineral oil at room temperature were used for the prediction, as the measured grinding temperatures were less than $30^{\circ} \mathrm{C}$ when using waterbased fluids and around $40-45^{\circ} \mathrm{C}$ for the mineral oil.

The results of CHTCs for water based fluids (Table 2) are reasonably close to the predictions. The CHTC for mineral oil was significantly increased when increasing the wheel speed, which is inline with the theoretical analysis, as the fluid flow velocity enhances the forced convection behaviour of the fluids (Figure 7). The predicted values for both 
waterbased fluid and mineral oil are higher than the measured values. The reason for this could be that the fluid velocity is lower than the wheel speed, as the rough workpiece surface texture being ground drags the fluid flow and also that the actual fluid film thickness can be larger than $0.15 \mathrm{~mm}$ due to the existence of the fluid entrance wedge shown in Figure 4.

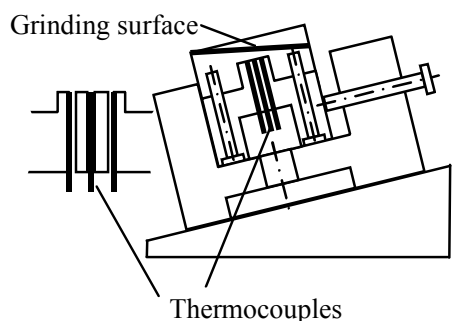

Figure 6: Inclined thermocouple test rig.

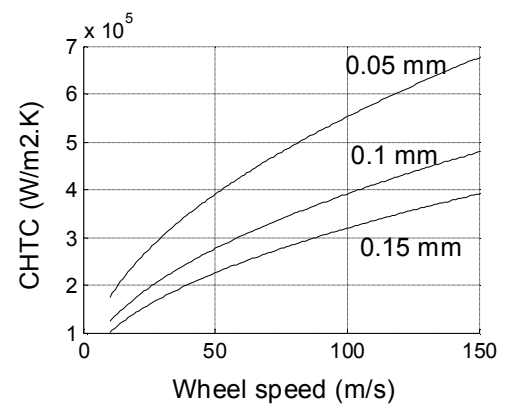

Figure 7: Change of CHTC, $h_{f}$, with wheel speed and fluid film thickness (mineral oil).

$\begin{array}{lcccc}\text { Fluid } & \begin{array}{c}\text { Vs } \\ (\mathrm{m} / \mathrm{s})\end{array} & \begin{array}{c}\text { SGE } \\ \left(\mathrm{J} / \mathrm{mm}^{3}\right)\end{array} & \begin{array}{c}h_{f} \text { measured } \\ \left(\times 10^{3} \mathrm{~W} / \mathrm{m}^{2} . \mathrm{K}\right)\end{array} & \begin{array}{c}h_{f} \text { predicted } \\ \left(\times 10^{3} \mathrm{~W} / \mathrm{m}^{2} . \mathrm{K}\right)\end{array} \\ \text { WB 1 } & 50 & 75.8 \pm 4 \% & 283 \pm 5 \% & 710 \\ \text { WB 2 } & 50 & 104.6 \pm 4 \% & 393 \pm 5 \% & 710 \\ \text { WB 3 } & 50 & 60.4 \pm 2 \% & 229 \pm 3 \% & 710 \\ \text { MO } & 50 & 36.9 \pm 17 \% & 71.4 \pm 20 \% & 220 \\ \text { MO } & 146 & 73.9 \pm 9 \% & 213 \pm 15 \% & 380\end{array}$

Table 2: Results of CHTCs from the tests

(WB: waterbased, MO: mineral oil).

\section{CONCLUSIONS}

Both theoretical analysis and experimental measurements show that the values of the CHTCs can be very high, much higher than the values previously reported. The CHTC values change with wheel speed and are also influenced by the value of the fluid film thickness. This film thickness in turn can be a function of wheel speed, porosity, grain size, coolant viscosity and flow rate. For deep grinding conditions (creep feed and HEDG), the upper bound value of fluid film thickness can be achieved due to the high coolant supply pressure and flow rate. The predicted CHTC values and trends show a relatively good agreement with the values estimated using the experimental approach.

Under the test conditions used in this study, the grinding temperatures were below $45^{\circ} \mathrm{C}$, so the temperature dependence of the thermal properties of the fluids does not have any significant effect on the $\mathrm{CHTC}$ predictions. The physical properties, e.g., viscosity and thermal conductivity of grinding fluid seem to have a slightly stronger effect on the sensitivity than the process parameters.

This preliminary study shows that it is possible to estimate the CHTC values within the grinding zone by using a theoretical analysis in combination with the experimental approach.

\section{ACKNOWLEDGEMENT}

The authors would like to acknowledge the financial support from EPSRC and Cranfield IMRC.

\section{REFERENCES}

[1] Malkin, S., 1974, Thermal aspects of grinding. Part 1Energy partition, Journal of Eng. for Industry, 96, 1177-1183

[2] Guo, C., Wu, Y., Varghese, V., Malkin, S., 1999 , Temperatures and energy partition for grinding with vitrified CBN wheels, Annals of CIRP, 48/1: 247-250..

[3] Jin, T., Stephenson, D. J., Rowe, W. B., 2003, Estimation of the convection heat transfer coefficient of coolant within the grinding zone, Proc. Institution of Mechanical Engineers, Part B, J of Engineering Manufacture, 217: 397-407

[4] Guo, C., Malkin, S., 1992, Analysis of fluid flow through the grinding zone, Journal of Eng. for Industry, 114, Nov., 427-434

[5] Engineer, F., Guo, C., Malkin, S., 1992, Experimental measurement of fluid flow through the grinding zone, Journal of Eng. for Industry, 114, Feb., 61-66

[6] Tsunasawa, Y., Aoyama, T., Inasaki, I., Yonetsu, S., 1982, Improvement of grinding fluid application in creep feed grinding, state of grinding fluid in the arc of contact, Trans. of the Japan Society of Precision Engineering, 48/11, p112

[7] Chang, C. C., Wang, S. H., Szeri, A. Z., 1996, On the mechanism of fluid transport across the grinding zone, Journal of Manufacturing Science and Engineering, 118, 332-338

[8] Szeri, A. Z., 1998, Fluid film lubrication, theory and design, Cambridge university press

[9] Schumack, M. R., Chung, J., Schulz, W. W., Kannatey-Asibu, Jr, E., 1991, Analysis of fluid flow under a grinding wheel, Journal of Eng. for Industry, 113, May., 190-197

[10] Jin, T., Stephenson, D. J., Corbett, J., 2002, Burn threshold of high carbon steel in high efficiency deep grinding, Proc. Institution of Mechanical Engineers, Part B, J of Engineering Manufacture, Vol. 216, 357364

[11] Hahn, R. S., 1962, On the nature of the grinding process, Proc. $3^{\text {rd }}$ Machine Tool Design and Research Conference, 129-154.

[12] Kim, N. K., Guo, C., Malkin, S., 1997, Heat Flux Distribution and Energy Partition In Creep-Feed Grinding, Annals of the CIRP, Vol. 46/1: 227-232

[13] Stephenson D. J., Jin, T., 2003, Physical basics in grinding, 1st European Conference on Grinding, Aachen, Germany, 6-7 November, K. Werner, F. Klocke, E. Brinksmeier (Eds.), Fortschr-Ber. VDI 2/ 643, VDI Verlag, 1301-1321 